Territorios 33 / Bogotá, 2015, pp. 13-32

ISSN: 0123-8418

ISSNe: 2215-7484

Procesos de ocupación del territorio, historia urbana y patrimonio II

\title{
Tres elementos modernos del patrimonio urbano difuso en Tunja, Boyacá
}

Three Modern Elements of Urban Heritage Diffuse in Tunja, Boyacá

Três elementos modernos do patrimônio urbano difuso em Tunja, Boyacá

Adriana Hidalgo-Guerrero*

Recibido: 15 de septiembre de 2014

Aprobado: 24 de abril de 2015

Doi: dx.doi.org/10.12804/territ33.2015.01

Para citar este artículo:

Hidalgo, A. (2015). Tres elementos modernos del patrimonio urbano difuso en Tunja, Boyacá. Territorios, 33, 13-32. Doi: dx.doi.org/10.12804/territ33.2015.01

* Arquitecta, Universidad Nacional de Colombia. Doctora en Periferias Sostenibilidad y Vitalidad Urbana por la Universidad Politécnica de Madrid. Investigadora del grupo NODOS y Directora del Proyecto "El cibermuseo: un medio para reconocer el patrimonio urbano difuso de Tunja”. Docente Titular, Universidad de Boyacá. Correo electrónico: adrbidalgo@uniboyaca.edu.co, adrhidalgoacademia@ gmail.com. 
Palabras clave

Desarrollo urbano, historia cultural,

patrimonio cultural, ecomuseo, modernización.

Keywords

Urban development, cultural history, cultural beritage, ecomuseums modernization.

Palavras-chave

Desenvolvimento urbano, bistória cultural, patrimônio cultural, ecomuseu, modernização.

\section{territarias 33}

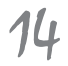

\section{RESUMEN}

El texto da cuenta de resultados de investigación referidos a la documentación de tres elementos representativos del patrimonio difuso de Tunja, en este caso, aquellos que configuran la denominada ruta de la modernidad, para su incorporación al ciberecomuseo Mutua. La investigación desarrollada es de tipo cualitativa e incorpora acciones de consulta documental, indagación en terreno y consultas a expertos. El proceso ha evidenciado una dinámica reflexiva acerca del valor y la pertinencia de los bienes identificados y de los temas que los objetos urbanos son capaces de contar, dada su supervivencia en la historia como huellas representativas de valores urbanísticos, arquitectónicos y testimoniales que podrían llegar a tener un reconocimiento patrimonial, en tanto expresan singularidades y configuran la identidad local.

\section{ABSTRACT}

This paper shows some of the research results of the project named The Cyber-museum: a way to recognize urban heritage in Tunja. It shows the results of one of the proposed activities about the documentation of three representative elements of diffuse heritage in that medium size Colombian city in order to incorporate that information in the Mutua Cyber-eco-museum. Those elements configure the so called "modernity route". The developed research was qualitative; it incorporated documental review, field work and expert consultances. The process evidenced a reflexed dynamic about the values and pertinence of identified goods and the subjects that these urban objects are able to express because they have survived in history as representative marks of urban, architectural and testimonial values that could be recognized as they express singularities and develop local identity.

\section{RESUMO}

$\mathrm{O}$ texto da conta de resultados de pesquisa referidos à documentação de três elementos representativos do patrimônio difuso de Tunja, neste caso aqueles que configuram a denominada rota da modernidade, para sua incorporação ao cyber-ecomuseu Mutua. A pesquisa desenvolvida é de tipo qualitativa e incorpora ações de consulta documental, indagação em terreno e consultas a expertos. O processo tem evidenciado uma dinâmica reflexiva acerca do valor e a pertinência dos bens identificados e dos temas que os objetos urbanos são capazes de contar dada a sua supervivência na história como rastros representativos de valores urbanísticos, arquitetônicos e testemunhais que poderiam chegar a ter um reconhecimento patrimonial em tanto expressam singularidades e configuram a identidade local. 


\section{Introducción}

Este artículo, resultado de investigación, se deriva del proyecto "El cibermuseo: un medio para reconocer el patrimonio urbano difuso de Tunja". ${ }^{1}$ La investigación, de la cual se presenta aquí una de sus etapas culminadas, se orienta hacia el reconocimiento y la divulgación de testimonios y marcas referenciales inherentes a procesos urbanos e históricos registrados en Tunja, que, debido a su significado, pueden considerarse como patrimonio, aunque carecen de reconocimiento por parte de las autoridades.

El trabajo se inscribe en las actividades del Museo Territorial Urbano de los Andes Nororientales, Mutua, un espacio de investigación y divulgación concebido desde 2007 como lugar de reflexión sobre la vida y desarrollo urbano de los diferentes asentamientos de la región y el territorio. Su intención es reflexionar y aportar a la construcción de la identidad urbana y promover la recuperación de la memoria. Mutua se dedica a identificar cuáles elementos físicos de carácter patrimonial, los colectivos construyen como referentes, cómo se articulan territorialmente y cómo se expresan en este, para ofrecer lineamientos, proporcionar criterios y derivar instrumentos para intervenciones propositivas. Pretende, por medio del diseño, recuperación y reorganización de las referencias urbanas, fortalecer el sentido de pertenencia.

El caso de esta investigación ha permitido construir una ruta museográfica dentro del proceso de consolidación urbana que habla de una pretendida modernidad para la ciudad de Tunja

La investigación emprendida, de tipo descriptivo y enfoque cualitativo, consta de varias etapas, en una primera se hizo la selección de ocho elementos que compondrían la colección de objetos del patrimonio difuso de Tunja y se determinaron tres rutas temáticas.

La segunda etapa ha tratado de responder a la pregunta sobre ¿qué valores arquitectónicos, urbanísticos y culturales tienen los objetos seleccionados y qué temas traen a la reflexión? A partir de esta documentación se continuará con la tercera etapa que consiste en la construcción de la plataforma interactiva, con la cual Mutua, por medio de un Ciberecomuseo, ${ }^{2}$ pretende comunicarse con la sociedad y encontrar estrategias de apropiación social de dichos elementos, en concordancia con la necesidad de laboratorios territoriales de verificación y validación de estos.

Este texto da cuenta del cumplimiento del objetivo de la segunda etapa, es decir, de documentar los tres elementos seleccionados desde una perspectiva arquitectónica, urbanística y temática.

Los objetos seleccionados se encuentran en el territorio urbano de Tunja. En la primera parte del texto se definen algunos referentes teóricos, en especial aquellos asociados con la idea del ecomuseo y la noción de patrimonio difuso considerados en la escogencia de los elementos. Seguidamente, se explica la metodología y las actividades desarrolladas.
${ }^{1}$ Investigación liderada por el grupo Nodos de la Universidad de Boyacá y cofinanciada entre esta Institución y el Departamento Administrativo de Ciencia, Tecnología e Innovación de Colombia (Colciencias), tras ser seleccionada en la convocatoria 609 de 2013 de Colciencias, "Arte, Cultura y diálogo de saberes”, enmarcada en el programa nacional de Ciencias Sociales y Humanas, en la linea "Patrimonio e innovación”. También hacen parte del proyecto los grupos investigativos Edutic, Giprocasy Ethos de la Universidad de Boyacá. A su vez, se encuentra articulada con la Red de Museos de Boyacá y la Red de Museos de Tunja y cuenta con el apoyo de la Escuela Taller de Boyacá. La propuesta consiste en la creación y puesta en funcionamiento del Museo Territorial Urbano de los Andes Nororientales (Mutua), concebido como un espacio en Internet que apunta a la recopilación, divulgación, valoración y eventual intervención de diferentes expresiones patrimoniales, tanto materiales como inmateriales, carentes de un reconocimiento masivo y de declaratoria monumental.

${ }^{2}$ Mutua documenta y reproduce en su plataforma de Internet referentes pa-

territarias 33 
trimoniales del territorio con el fin de otorgarles visibilidad, propiciar su estudio e interacción con la comunidad local como base para eventuales programas de intervención (bttp://cibermutua.co/).

${ }^{3}$ Es posible señalar que Tunja mantuvo construcciones de los siglos XVI, XVII $y$ XVIII, producto de la colonia española, hasta los años cincuenta, con muy poco crecimiento, con densificación de los espacios interiores de sus originales manzanas orto reticulares, y con la introducción de edificaciones republicanas en los siglos XIXY principios del $X X$, que mantenian el perfil de alturas de uno a dos pisos, el uso de materiales y técnicas tradicionales de construcción, como el adobe o la tapia pisada, las cubiertas en teja de barro, entre otros, que le daban a la ciudad un aire de pueblo congelado en la historia. Cuando se inician construcciones que usan nuevos lenguajes estilísticos, propios de la arquitectura del movimiento moderno europeo, se introducen nuevas técnicas constructivas y materiales no tradicionales como el concreto reforzado $y$ el acero, $y$ se implantan edificaciones en altura, llega la pretendida modernidad con la construcción de objetos representativos de

\section{territarios 33}

A continuación, se presentan los resultados obtenidos del análisis de los tres elementos que corresponden a la ruta denominada "La modernidad" 3 en el guión museográfico de Mutua: (1) Aeropuerto Rojas Pinilla, (2) Normal de Varones y (3) Silos del INA (ver figura 1). ${ }^{4}$

Finalmente, se esbozan conclusiones derivadas de esta etapa de trabajo.

\section{Fundamentos conceptuales y referenciales}

Los bienes de interés cultural arqueológico, arquitectónico y urbanístico en el territorio cundiboyacense son un patrimonio de gran interés histórico y, de hecho, constituyen una atracción turística y un soporte al desarrollo sostenible regional. Sin embargo,

Figura 1. Localización de los tres elementos en Tunja

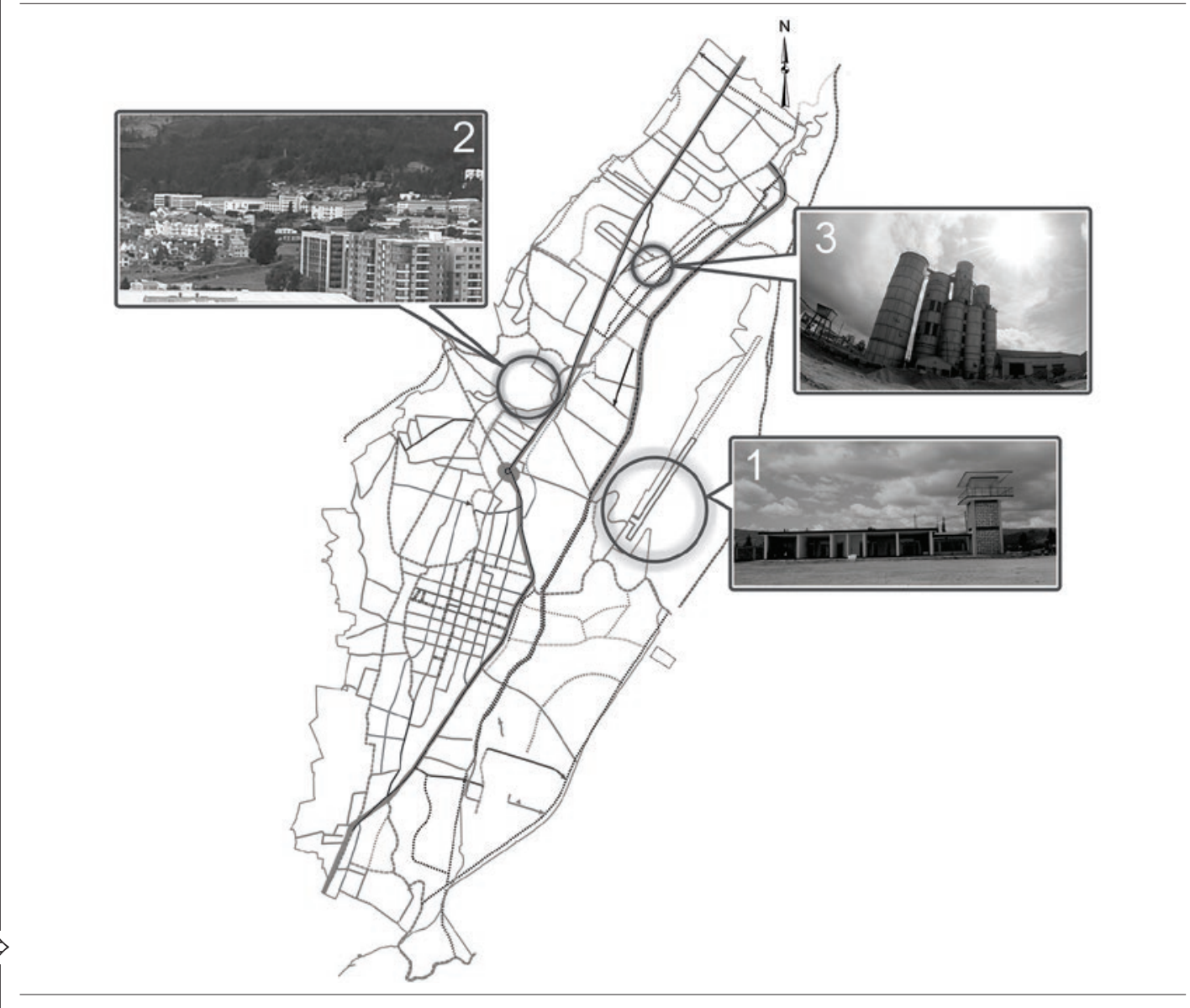

Fuente: elaboración de D. Ruíz, basada en Planos e Imágenes de A. Hidalgo. 
el desconocimiento de su existencia, o el estado de deterioro en que se encuentran las señales, supone una amenaza al valor cultural e histórico de dichos bienes.

Ahora bien, su correcta identificación, valoración y conservación puede conducir a un proyecto del carácter de ecomuseos o de itinerarios culturales que permita superar problemas comunicativos entre la comunidad y los científicos, empoderar a las comunidades para que valoren y hagan valorar su cultura, al hacer uso de su patrimonio en beneficio de sí mismos y superar las aproximaciones individualistas a los objetos del museo (Decarli, 2003).

Mutua pretende poner en valor el acervo cultural a partir de la didáctica, utilizando algunas premisas pedagógicas por medio de recorridos concebidos como itinerarios culturales, a partir de temas y sitios que no corresponden a aquellos habitualmente visitados por el turismo, pero que cuentan con una estructura integral con actividades, personas, hitos y costumbres.

\subsection{Mutua como ecomuseo}

La proximidad de Mutua con el concepto de ecomuseo se origina en una relación de influencia con un equipo de expertos italianos que han colaborado con nosotros desde hace algunos años. Se trata de Maurizio Boriani, ${ }^{5}$ Maria Cristina Giambruno ${ }^{6}$ y María Grazia Folli, 7 quienes, desde el Politécnico de Milán y, en particular, desde el Dipartimento di Progettazione Dell'architettura, trabajan en líneas de investigación muy vinculadas a las nociones de territorio, paisaje, restauración y proyectación. Fue por ellos que se comprendió que los ecomuseos dialogan con los objetos de sus colecciones de una manera no convencional en la que el concepto de arquitectura y patrimonio "diffuso":

Se entiende como un territorio caracterizado por ambientes de vida comunes y tradicionales, patrimonio natural, histórico y artístico, que tiene valor y características no monumentales pero "difusas”. Es un área no definida realmente por límites geográficos, sino más bien por cualidades de homogeneidad cultural, así como por aspectos antropológicos, costumbres y maneras de vivir y de interrelacionarse entre sus habitantes (Nota 6 de A. Batistelli en Boriani, 2014).

Barreto (1993) afirma que en 1971 el término ecomuseo fue creado por Hugues de Varine al referirse a un espacio de relación entre la comunidad y su territorio con el fin de preservar la memoria y reencontrarse con su cultura.

Los ecomuseos surgen como alternativa a aquellos tradicionales que trasladan los objetos a exhibir a un edificio ajeno a las condiciones contextuales donde el objeto fue creado. La mirada coleccionista empieza a perder vigencia cuando Unesco/ ICOM indican la necesidad de orientar la institución museo hacia dinámicas de investigación, preservación y difusión del patrimonio con las comunidades, lo que origina el movimiento de la nueva museología (Decarli, 2003). las ideas de progreso, desarrollo y civilización y que a partir los años cincuenta generaron amplios debates a favor o en contra del mantenimiento de la tradición (Medina, 2007).

${ }^{4}$ El guión museográfico completo se fundamenta en tres ejes: (a) la modernidad que dejó de serlo, (b) historia e historias en piedra y adobe, $y$ (c) ruralidad urbanizada (Llanos é Torres, Inédito).

${ }^{5}$ Linea: il progetto di conservazione del costruito e del paesaggio.

${ }^{6}$ Intereses investigativos con Mauricio Boriani en la conexión entre preservación, intervención en los bienes patrimoniales, planificación del territorio y comprensión del paisaje a la vez que amplían la noción de monumento a diversas categorias (Boriani \& Giambruno, 2008).

${ }^{7}$ Linea: casa e città.

territarias 33

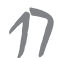


El interés de las instituciones museológicas latinoamericanas, sobre la necesidad de desarrollar los mecanismos que les permita trabajar con la comunidad en la protección del patrimonio y de hacer copartícipes a la comunidad en las políticas y decisiones del museo, ha sido puesto de manifiesto reiteradamente en diversos foros. Desde luego no muy frecuentemente estas expresiones de deseo y compromisos son llevadas a la práctica, pero sin duda son indicadores de una conciencia institucional sobre esta problemática (Decarli, 2003, p. 2).

$\mathrm{Al}$ ecomuseo que desarrolla Mutua le importa ser un puente entre la academia y las comunidades para las cuales se trabaja. Se interesa en las huellas patrimoniales con el ánimo ser un actor activo que guía procesos de preservación y fortalecimiento de la memoria urbana, usando el territorio como espacio museístico. Estos aspectos son expuestos por la nueva museología y museología crítica que, si bien no es nueva aún, tiene incipiente desarrollo en la región.

De acuerdo con la museología crítica, los museos han de convertirse en espacios para la "acción comunicativa", donde el visitante sea confrontado con los dilemas de la sociedad contemporánea a través de los ojos de la historia y la memoria crítica y con una perspectiva ética. Los museos deben confrontar la controversia y hacerla explícita (Navarro, 2006, p. 3)

\section{tersitarias 33} 18 elementos como hitos arquitectónicos, conjuntos urbanos, esculturas, etcétera, donde es posible la educación formal o informal y la orientación hacia diversos públicos (Pastor, 2004).

\subsection{Criterios del patrimonio difuso}

Un aspecto importante en los elementos identificados es que no cuentan con un reconocimiento legal o normativo que lo proteja, pero podrían contar con reconocimiento social derivado de su uso y del sentido que tienen como huellas del proceso histórico de conformación urbana, su capacidad de contar historias desde sus valores testimoniales, urbanísticos y espaciales. Son objetos dispersos en el territorio $\mathrm{y}$, detrás de ellos, hay agentes y actores que propiciaron cambios en la sociedad del momento en que surgen, de la cotidianidad en su uso, al igual que hablan de temas clave de la historia local, pero también regional y nacional.

Los criterios de selección de los elementos revelan confluencia entre ellos, su contexto y los usuarios dentro de una dinámica histórica de nexos y cambios sociales, culturales o económicos.

Un grupo de cuatro criterios determinaron el proceso de selección de los elementos del patrimonio difuso de la primera muestra: (a) no son monumentales ni cuentan con declaratoria oficial como patrimonio y, en sintonía con Aguirre (2007), pueden denominarse como patrimonio modesto vernáculo u otro patrimonio; (b) remiten a diversos momentos históricos 
y referentes culturales; (c) pueden conllevar a reutilizaciones y apropiaciones colectivas que los protejan y preserven para el futuro; (d) descentralizados y posiblemente dispersos e incluso hasta invisibilizados por otros elementos que los hacen pasar desapercibidos total o parcialmente o hacer que su huella se soslaye u olvide. (Llanos, Hidalgo \& Torres, 2014).

\section{Materiales, métodos y procedimientos}

En un primer acercamiento a los elementos para la colección se recogieron de los trabajos de Hidalgo (2010, 2014, 2012), Llanos (2012), Del Carpio (2014), entre otros. Es así, como entre investigadores y asesores se candidatizaron veintidós objetos y se seleccionaron ocho, para que con estos se definiera un guion museográfico $y$, finalmente, se amplió la información de dichos objetos por medio de documentos, estudio de imágenes y testimonios que brindaron mayor información referente a sus valores (estéticos, patrimoniales, urbanos y referenciales).

Con la información de base se escriben textos descriptivos y analíticos de los hallazgos y se elabora la cartografía de soporte.

\section{Resultados}

Aspectos importantes que se detectaron con la selección de la muestra fue reconocer la resistencia a una modernidad soñada que guarda objetos que responden simultáneamente a un entorno tradicional y rural contrapuesto a otro urbano en proceso de urbanidad.

A continuación, se detalla la documentación ${ }^{8}$ de los tres objetos que pertenecen a la ruta que habla de una modernidad que dejó de serlo, ${ }^{9}$ a partir de sus valores, como objetos sin reconocimiento patrimonial oficial, su carácter descentralizado y disperso, los valores arquitectónicos y urbanísticos propios y de su injerencia en el crecimiento de su entorno dentro del proceso de modernización físico-espacial de Tunja y el reconocimiento de su estado actual de funcionamiento o abandono.

\subsection{Instalaciones del aeropuerto Gustavo Rojas Pinilla}

$\mathrm{Al}$ inaugurarse en el periodo de gobierno del presidente Rojas, se le hace un homenaje al ser oriundo de Tunja y protagonista del impulso modernizador como varias de sus obras en el resto del país (García, 2007; Ortega, Fariña, \& Junior, 2013).

Sus instalaciones están aún en pie y relativamente bien conservadas, sin embargo, no ha funcionado regularmente nunca, aunque ha tenido varias reinauguraciones.

Se conoce que los planos se contrataron mediante el Acuerdo Municipal de Tunja No. 9 del 2 mayo de 1949 a la firma del teniente coronel Carlos J. Salcedo, pero no se saben mayores datos de la edificación. Aun así es importante destacar algunos de sus valores arquitectónicos insertos en una estética propia del movimiento moderno de carácter internacional.
${ }^{8}$ Se trata de describir los valores arquitectónicos, urbanísticos de los elementos, así como los temas que traen a la reflexión, por ende no se concentran en los edificios sino en los desarrollos del entorno que pudieron propiciar, pues en sus orígenes fueron edificaciones aisladas del tejido urbano y en el presente están inmersosen él. En adición, son los textos con los cuales se pretende alimentar los de la plataforma virtual de Mutua.

9 Al hablar de una modernidad que dejó de serlo (Llanos, Hidalgo \& Torres, 2014), se insinúa que la modernidad en Tunja se confundió con modernización tecnológica, pero esta sería una hipótesis a demostrar por medio de otros trabajos de investigación. territarios 33

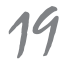


${ }^{10}$ Acuerdo N. ${ }^{\circ} 16$ de 1948 del Concejo Municipal de Tunja donde se apropian 2000 pesos para hacer efectiva la norma.

\section{territarias 33} 20
Para Norberg-Schulz (2005), la arquitectura moderna nació para dar confort al hombre en un mundo nuevo, valorar la novedad y transformarse, formalmente diferenciarse del pasado, aspectos que son visibles en la edificación de la torre de control. Una primera ruptura está en la sencillez de las formas y la desnudez de los materiales que se heredan de la filosofía del neoplasticismo holandés, que aboga por la simplificación formal, el paso del bloque cerrado al abierto, la asimetría en la composición y la preocupación por la escala humana (Benevolo, 2008). Igualmente, se encuentra influencia del maestro Mies Van der Rohe con su máxima "menos es más", al igual que de otras corrientes artísticas de vanguardia en la primera mitad del siglo Xx, como el cubismo. Por su parte, Miranda (2005) afirma que la arquitectura es verdadera cuando no se respalda en pretensiones estéticas.

Es así como se reconoce en la edificación una composición arquitectónica absolutamente sencilla, sin ninguna demanda, más allá de albergar su función, mostrar los materiales con los que ha sido construida y la racionalidad constructiva en la modulación de sus partes.

La fachada está conformada por dos cuerpos, uno francamente horizontal subdividido en cinco módulos, la torre, ubicada asimétricamente sobre el costado norte se compone de tres módulos completando una L. En medio de ambos, un cuerpo de menor altura realiza la conexión compositiva, como remate, los techos conforman una línea horizontal muy delgada.
En cuanto a los materiales, se evidencia el uso del concreto en la estructura y placas de cubierta, material versátil que permite esbeltez. La torre está recubierta por ladrillos modulares que conforman una celosía, lo que facilita la ventilación natural, pero aísla. En el interior del cuerpo horizontal se destaca el uso de piedra a la vista.

En cuanto a su valor urbanístico, el objeto aeropuerto, en especial su pista, por necesidades del pretendido servicio, se ha constituido en una barrera al crecimiento hacia el sector oriental de Tunja. En primera medida, se encuentra en la parte alta de una loma denominada del Zaque, donde el 26 de junio de 1948 se declara de utilidad pública el terreno para edificar el aeródromo. ${ }^{10}$ En el momento en que se ejecuta (años cincuenta), no existía casi ningún desarrollo urbanístico en el área con excepción de las instalaciones del Batallón Bolívar (1939), que también configuraban un polígono dotacional, aislado del trazado urbano sobre un antiguo camino que conducía a Toca. Al revisar la evolución del entorno en las aerofotografías (ver figura 2), se observa que, hacia 1957 , la única variación en el entorno es un nuevo camino que se construye hacia el aeropuerto para conectarlo con la carretera Central del Norte. En la imagen de 1979 se observan nuevas construcciones sobre el camino al aeropuerto como el estadio y la casa para el gobernador de Boyacá. En 1989 se puede observar un importante desarrollo del contexto del lugar, en los alrededores del aeropuerto se halla el cerramiento de la cárcel municipal, 
Figura 2. Evolución sector Aeropuerto Rojas Pinilla de Tunja

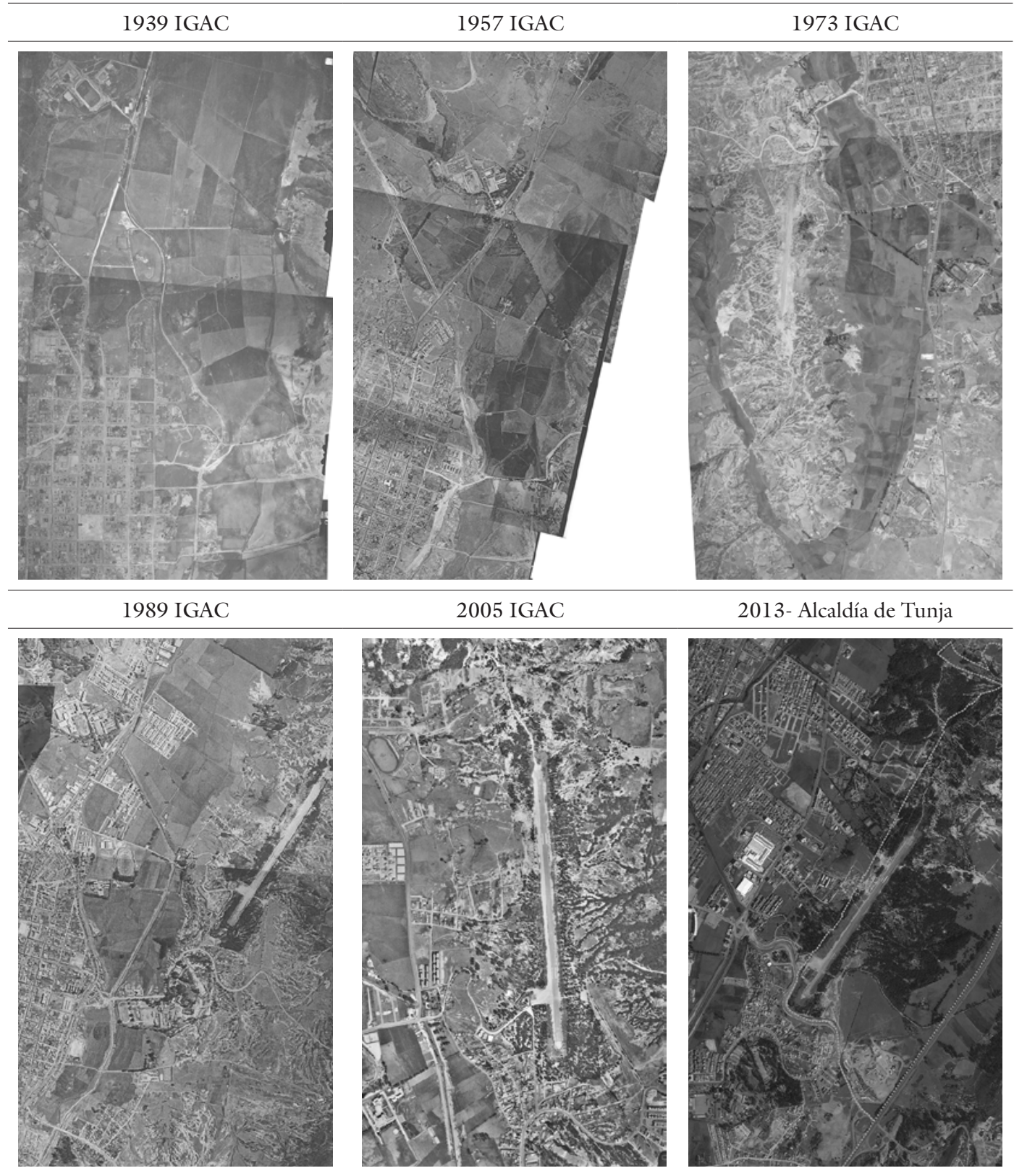

Fuente: elaboración propia a partir de fuentes indicadas. 
11 Nombre que esta agrupación toma por analogía con el aeropuerto bogotano.

\section{territarias 33}

22 la urbanización informal de los barrios La Esmeralda y El Dorado. ${ }^{11}$ Igualmente, las instalaciones de la Villa Olímpica se complementan y surgen barrios formales como Mesopotamia y Santa Inés.

En el año 2005, y gracias a la construcción de la Avenida Universitaria sobre el valle del río Jordán, los barrios del área crecen y surgen nuevos conjuntos, especialmente gated comunities cercanos a la pista del aeropuerto, pero con ninguna relación con este. De modo similar, las urbanizaciones informales continúan su consolidación. Para 2013 se aprecia una gran cantidad de crecimientos formales e informales que alcanzan los límites del predio del aeropuerto en su costado occidental, pero que en realidad están vinculados a la vía universitaria y a la construcción de Unicentro en el valle. Este recorrido permite afirmar que el aeropuerto no fue un elemento que actuase como polo de desarrollo del sector, como sí lo fueron las vías.

\subsection{Escuela Normal de Varones}

Se asocia el origen del conjunto con las celebraciones del IV centenario de Tunja a finales de la década del treinta, gracias al fomento del Ministerio de Obras Públicas, que realizaba recomendaciones modernas para el dimensionamiento y orientación de las aulas. Precisamente, una de las familias estilísticas adoptada y desarrollada, fue aquella que incorporaba proyectos modulares, de planta simétrica, volumetría prismática y decoración parca. (Hidalgo, 2012, 2014; Niño, 1999)
El número 1226 del periódico El Boyacense (27 de enero de 1928, p. 27) informó que los planos de la edificación serían contratados con una firma de Bogotá y en 1937 ya funcionaban dos pabellones. Una placa ubicada en la antigua Escuela Anexa ubica su construcción en 1937 por parte del ingeniero Jorge Valvuena durante la administración de José Joaquín Castro Martínez.

El aspecto urbano que más llama la atención es la localización periférica por la que se optó para desarrollar el conjunto, la cual puede obedecer a la necesidad de diferenciarse del trazado antiguo y colonial de la ciudad. De esta forma, se produce la denominada "discontinuidad urbana producida por la localización de modernos equipamientos a cargo del sector público" (Hidalgo, 2010).

El investigador Carlos Niño Murcia (1999) indica que el diseño arquitectónico fue de Pablo de la Cruz en 1935, quien siguió un estilo denominado "vernácular modesto". Aunque el proyecto no se ejecutó exactamente como los planos originales, es posible reconocer tres elementos originales que subsisten hoy:

1. El bloque central con aulas, teatro, capilla y dormitorios.

2. La escuela anexa a la Normal.

3. Una cancha de futbol.

Al revisar la planta del primer edificio de Normal de Varones se observa estricta simetría en la composición arquitectónica, 
que acude a conformar un patio o claustro modernizado con proporción rectangular. El lenguaje de las fachadas se define como premoderno, ya que carece de ornamento, acude a proporciones horizontales aun cuando sigue el dominio clásico de la simetría.

Frente al patio central, se localizaría un gimnasio y una escuela tipo que no se ejecutaron conforme a dichos planos, pues esta última se construye en el costado norte del primer edificio y rompe con la idea original de simetría del conjunto. En planta, su composición arquitectónica se caracteriza por conformar un claustro de una crujía, en la volumetría se aprecia el acercamiento al cubismo y la experimentación de vanos horizontales.

Posteriormente, en la década del cincuenta, se construye un cuarto elemento para el colegio de educación media, hoy llamado Escuela Normal Superior de Santiago de Tunja, dado que las anteriores edificaciones adquirieron un carácter universitario con la implementación de la Universidad Pedagógica. Esta edificación acude a una composición evidentemente moderna, con el abandono de las ventanas de proporción vertical separadas, que son reemplazados por ventanales continuos que conforman una fachada corrida. Adicionalmente, en el primer piso es posible observar las columnas dispuestas en estricta modulación y que permiten que no se requieran muros estructurales, dejando la planta libre y una sensación de que los dos pisos superiores flotan en el espacio gracias al uso del voladizo.
La planta general es una $\mathrm{T}$ que conforma dos volúmenes a manera de prismas rectangulares, con predominio de la proporción horizontal. De manera análoga a sus antecesores, se aprecia el acercamiento al cubismo, la visualización de la estructura tal cual es, la ausencia de ornamento y el uso purista del color blanco.

El campus de la Universidad Pedagógica, que finalmente se transforma en Universidad Pedagógica y Tecnológica de Colombia (UPTC), sigue su desarrollo con nuevas edificaciones, pero esa sería otra historia. Fue el núcleo inicial el que evidentemente se constituyó en un polo de desarrollo urbano para la ciudad y que le otorga al sector norte un uso educativo preferencial ${ }^{12} \mathrm{e}$ incidido en el desarrollo urbanístico, como se puede apreciar en la figura 3, en 1939 el aislamiento del conjunto respecto de la ciudad es evidente. Para 1957 se mantiene el aislamiento respecto de la ciudad, en tanto el campus crece con otras edificaciones, también se observan nuevas vías o la rectificación de las existentes. En 1973 se observa un crecimiento en barrios formales, aislados de toda trama, que nacen en el entorno como Pozo Donato, La María y San Rafael (Instituto de Crédito Territorial, ICT); de equipamientos educativos como la Normal Femenina y la consolidación del área influencia del ferrocarril y Avenida Norte, sin mayor planeamiento. Para 1989 se aprecia un significativo crecimiento de barrios dependientes de la Avenida Norte, que envuelven el campus original de la Normal, que pasa a ser más centro que periferia. Nacen nuevos barrios formales
${ }^{12}$ Es de anotar que el Plan Piloto de 1958 determinó un uso predominantemente educativo para la zona, debido, precisamente, a la localización de este campus (AUA, 1958). territarias 33

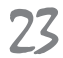


Figura 3. Evolución urbanística sector Normal de Varones

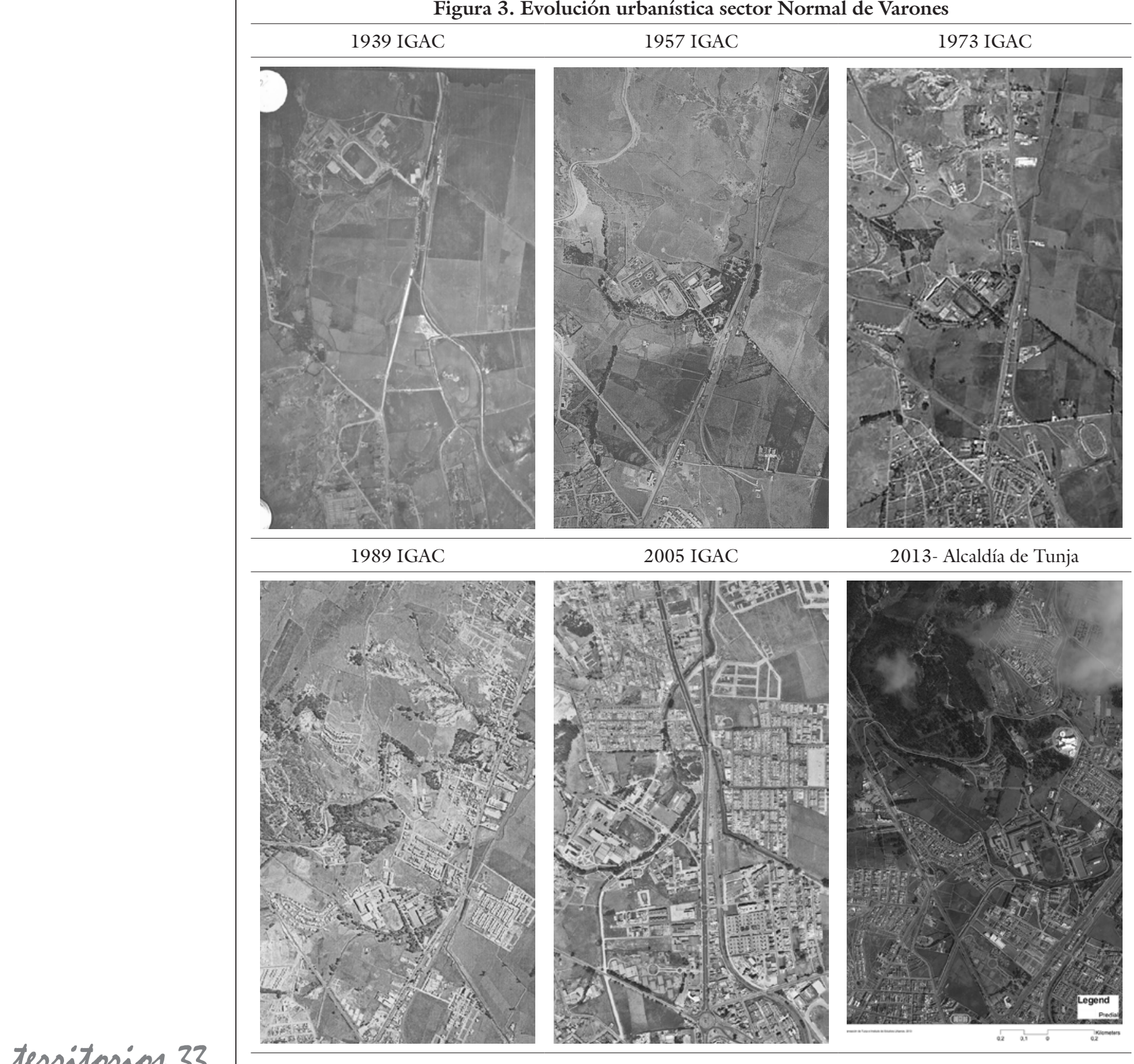

territarias 33

Fuente: elaboración propia a partir de fuentes indicadas.

24 
como Rosales, Canapro, Santa Inés, Mesopotamia y el barrio de los profesores de la UPTC, dentro de su campus llamado La Colina. Equipamientos como el parque Recreacional del Norte rellena espacios entre el campus y la ciudad.

Los procesos de consolidación de barrios y equipamientos continúan hacia 1989 y se refuerzan en los años siguientes, como se observa en las aerofotos de 2005 y 2013 , por una parte, asociado con las actividades y usos que la Universidad produce en su entorno inmediato y, por otra, a las dinámicas y demandas de crecimiento del norte de la ciudad. El costado occidental, por su parte, se mantiene sin desarrollo urbano por la topografía abrupta y porque la parcela de la Universidad es muy extensa, superando incluso la carretera hacia Arcabuco, Bucaramanga.

\subsection{Silos del INA}

El conjunto de los silos de Tunja es capaz de contarnos historias sobre el proceso de modernización de Tunja en el siglo xx, que ha modificado el paisaje urbano. Por ende, merece ser conocido, reconocido, preservado y resignificado como seña territorial de identidad. ${ }^{13}$ Es un conjunto que expone la masiva industrialización de la década del cincuenta, que se produce en la región con impulso del gobierno central y, nuevamente, con la presidencia de Rojas Pinilla.

La responsabilidad de edificar el conjunto de silos de Tunja recae sobre el Instituto Nacional de Abastecimiento (INA), entidad nacional creada en 1944 en el go- bierno de Alfonso López Pumarejo, con fundamento en la Ley 7 de $1943 .{ }^{14}$ Posteriormente, la entidad se reestructura con el nombre de Instituto Nacional de Mercado Agropecuario (IDEMA) ${ }^{15}$ y cuando esta desaparece, el conjunto es dado en arriendo a una entidad llamada Trigonal S.A., que funciona allí hasta finales de la primera década del siglo XXI, cuando el Ministerio de Agricultura decide subastarlo. Actualmente, pertenece al Instituto de Recreación y Deporte de Tunja, entidad municipal, y existe el proyecto por parte de la Alcaldía de trasladar a este predio la Normal Superior. Este breve recorrido sobre sus propietarios caracteriza el proceso de nacimiento, desarrollo, crisis y decadencia del manejo estatal del fomento agrícola y del mercado agropecuario moderno. ${ }^{16}$

Hacia 1955 se empieza a configurar la zona industrial del norte, antes de que el Plan Piloto de 1958 determinara dicha función para la zona (AUA, 1958). Los Silos del INA se implantan allí gracias a la cercanía a la línea de ferrocarril del nordeste y la lejanía a la edificación residencial del momento. Se encuentra en este sitio una oportunidad para desarrollar la incipiente industria tunjana. Este espacio físico lo comparten los Silos, inaugurados en 1955, un grupo de bodegas que probablemente corresponde también a instalaciones del INA y a la Electrificadora de Boyacá en 1958.

Al observar las aerofotografías de 1957 del IGAC se identifica el aislamiento de dichas instalaciones en relación con el tejido urbano, su desarrollo apenas alcanzaba la zona de la Universidad Pedagógica, con-
13 Lamentablemente, en abril de 2015, la Alcaldía Municipal de Tunja inicia un proceso de demolición de la obra con el fine de chatarrización $y$, a pesar de la ardua campaña que desde cibermutua.co se realizó, no fue posible detener el proceso (ver figura 5).

${ }^{14}$ En su Articulo 4 se indicaba "Facúltase al Gobierno para fundar o subvencionar cooperativas de producción, distribución o consumo de productos alimenticios. Para el cumplimiento adecuado de esta autorización, podrá el Gobierno realizar las operaciones de crédito que sean necesarias".

15 Mediante Decreto Nacional 2420 del 28 de septiembre de 1968 en el cualel Ministerio de Agricultura del momento reestructura el Sector Agropecuario y en su Artículo 43. Denominación. A partir de la vigencia del presente Decreto, el Instituto Nacional de Abastecimiento (INA) se denominará Instituto de Mercadeo Agropecuario (IDEMA).

${ }^{16}$ Para complementar y confrontar esta historia pueden consultarse Martinez (1986), el Fondo $\mathrm{Na}$ cional Cerealista (FENALCE) (2007), Méndez (2007), Espinal, Martínez, $\Rightarrow$

territarios 33

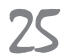


\& Prieto (2006) y las leyes, normas o decretos previamente citados.

${ }^{17}$ Del inglés "form follows function”

\section{territorias 33}

forme a lo que es posible observar en fotografías publicadas por la Revista Boyacá a raíz de su inauguración.

Otro indicador notable en la configuración urbana es el hecho de la angosta franja que se forma por los límites que impone la línea de Ferrocarril y la Antigua Vía a Paipa. Con el pasar de los años, y a pesar de que la ciudad crece notablemente hacia el sector norte, es posible identificar la misma franja industrial con escaso desarrollo en la actualidad, puesto que fueron pocos los lotes vecinos al INA que alcanzaron consolidación en 1973, 1989, 1996, 2005 y 2013, respectivamente (ver figura 4).

El área occidental de la franja oriental permanece vacante, de alguna manera, la barrera de accesibilidad a los predios del área que la línea del tren provoca impide desarrollar esta parte de la ciudad. Solamente desde la primera década del siglo XXI, y gracias a la puesta en marcha de la Avenida Universitaria, es cuando dicha zona comienza a despertar y termina convertida en un área de alta demanda para desarrollos inmobiliarios de los estratos más altos de Tunja. En las aerofotografías de 2005 y 2012 es posible evidenciar el surgimiento de nuevos tejidos residenciales y de equipamientos allí, aun cuando persiste la primacía de lotes vacíos que esperan ávidos a inversionistas que los desarrollen.

Por el contrario, la consolidación de barrios de vivienda cercana, en especial los tejidos con accesibilidad por la Avenida Norte, terminan rodeando el sector destinado a industrias por su costado occidental.
En consecuencia, este uso pierde vigencia pues deja de estar aislado y podría causar contaminación a las zonas residenciales, en tanto los vientos soplan hacia el norte. Se suma a esto el decaimiento del sector industrial en todo el país y el hecho de que Tunja se especializa en servicios y nunca desarrolló infraestructura o productividad industrial como tal.

La composición arquitectónica de la planta de Silos de Tunja, era constituida por la adición de diez a once cilindros con diversas alturas y diámetros, conectados por estructuras de comunicaciones verticales, tubos, embudos y casetas de maquinaria.

Es importante destacar que la construcción de silos en el mundo tiene una larga trayectoria que pasa por aquellos muy antiguos y subterráneos hasta los verticales que empiezan a construirse en el siglo XIX en Europa, y en el siglo Xx se intensifica la construcción de silos de hormigón o concreto reforzado y, finalmente, se popularizan aquellos fabricados en acero, como en el caso de los Silos de Tunja por sus ventajas económicas y técnicas.

La sencilla volumetría, no persigue tener nada más que lo que se requiere para cumplir su función de albergar productos agrícolas como trigo o cebada. Es un claro ejemplo de la aplicación de la máxima "la forma sigue a la función", ${ }^{17}$ principio que caracteriza toda la arquitectura moderna y contemporánea, donde se hace énfasis en la sencillez formal y el cumplimiento de la función para la que se hicieron. 
Figura 4. Evolución urbanística del sector Silos del INA

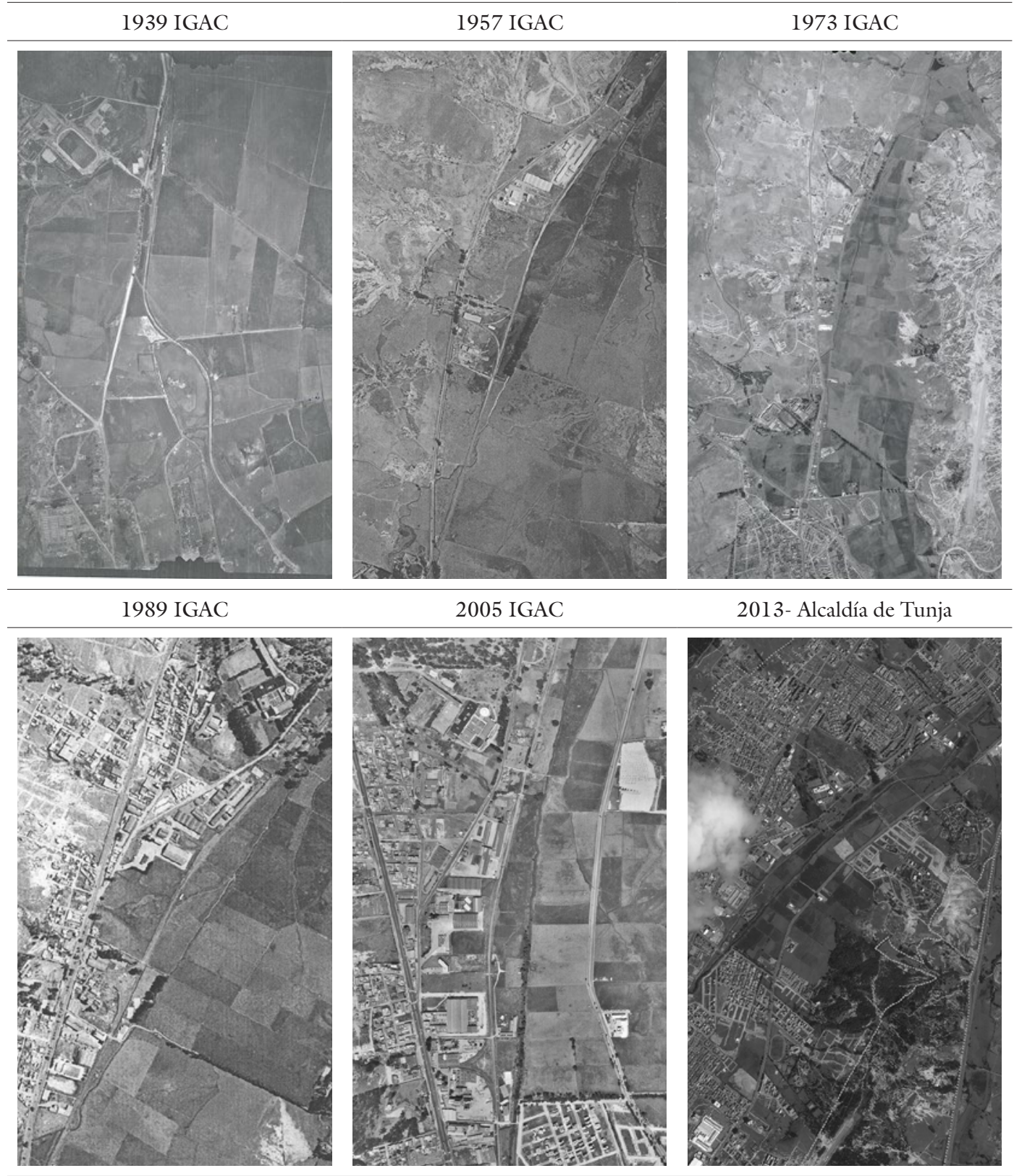

Fuente: elaboración propia a partir de fuentes indicadas. 


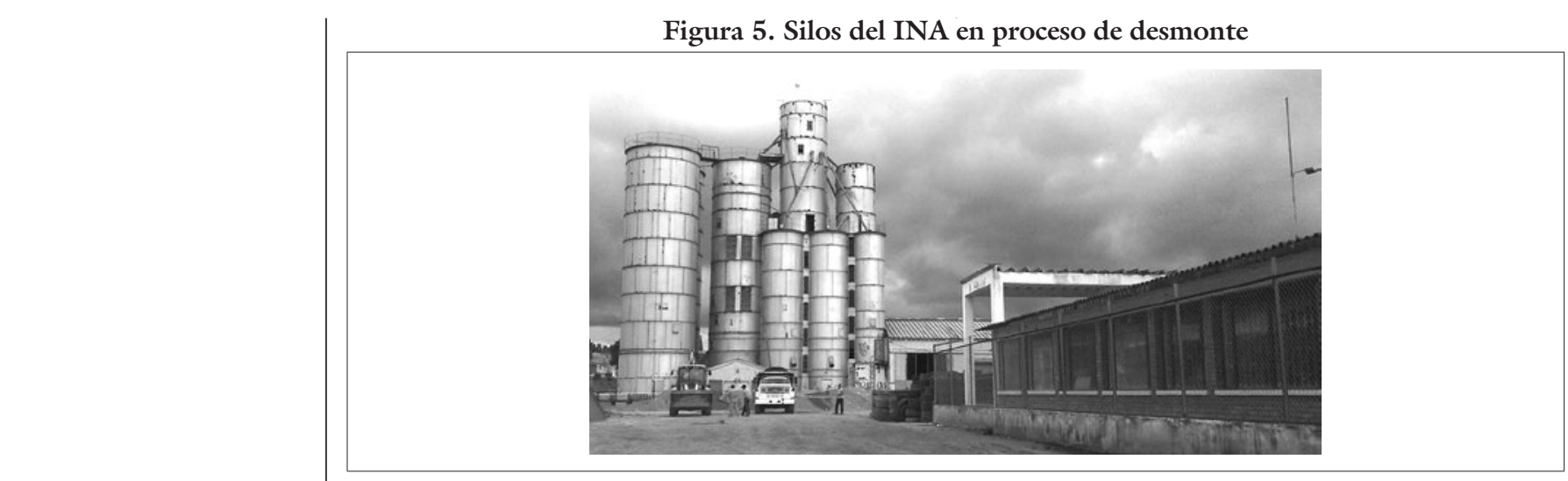

Fuente: Hidalgo (abril de 2015).

Figura 6. Mosaico de algunos valores arquitectónicos de los tres elementos

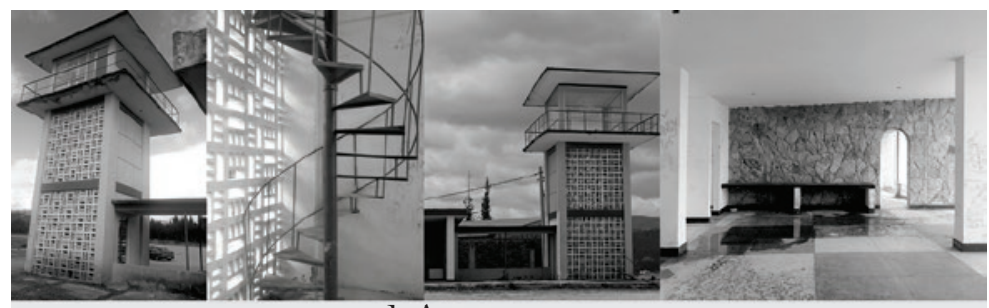

1. Aeropuerto

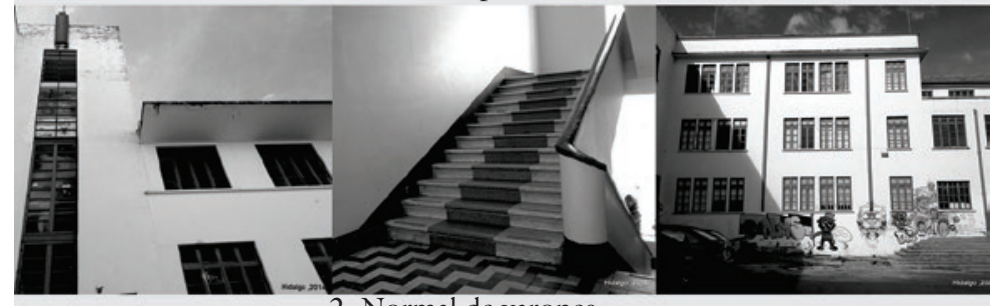

2. Normal de varones

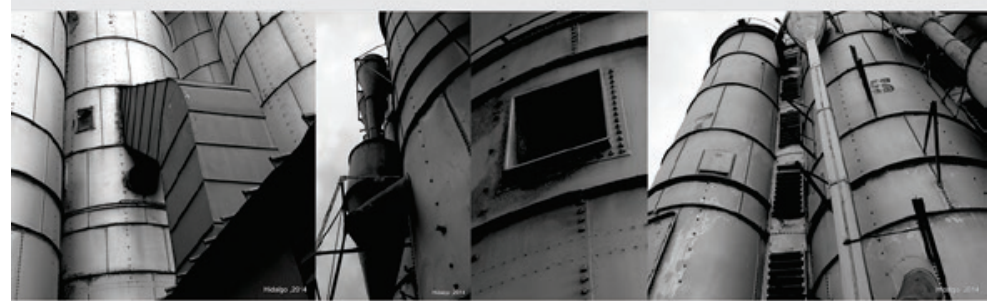

3. Silos 


\section{Conclusiones}

El proceso de selección y documentación de elementos del patrimonio urbano difuso de Tunja ha evidenciado una dinámica reflexiva acerca del valor y la pertinencia de los bienes identificados y de los temas que los objetos urbanos son capaces de contar, dada su supervivencia en la historia, son huellas de valores urbanísticos, compositivos y testimoniales que podrían llegar a tener un reconocimiento patrimonial, en tanto expresan singularidades y configuran la identidad local.

Los elementos de la ruta de la modernidad descritos en las páginas precedentes tienen la capacidad de remitir a valores arquitectónicos, gracias a sus cualidades formales, compositivas y singularidades; a valores urbanísticos, en tanto ayudaron a configurar el territorio de la periferia tunjana, sea como polos de desarrollo en el caso de la Normal de Varones y de los Silos del INA o como reductos de intenciones modernizadoras que no pudieron desarrollarse en el caso del Aeropuerto Rojas Pinilla (ver figura 6).

De igual manera, son huellas testimoniales de intenciones económicas y políticas que hablan de la historia colombiana en temas como el fomento a la educación, cambios conceptuales y metodológicos de la formación de maestros, fomento a la agricultura y el abastecimiento de alimentos o de la transformación en los sistemas de transporte. Pero también habla de las crisis y decadencia de dichas intenciones en la Colombia reciente y, por ende, pone a pensar de forma crítica en nuestra historia.
La documentación de los elementos descritos ha permitido confirmar que:

- No son monumentales, ni cuentan con declaratoria oficial como patrimonio.

- Dan cuenta de un proceso de modernización físico-espacial en sí mismos y por la injerencia que su presencia causa en el entorno y el crecimiento de Tunja, en el caso de la Normal de Varones, como elemento halonador del crecimiento hacia el norte con vocación en la especialización educativa, en los Silos como elemento referencial de la función industrial y en el caso del aeropuerto por propiciar la presencia de asentamientos informales y como barrera de crecimiento urbano, más allá de sus límites.

- Están descentralizados, dispersos e incluso pasan desapercibidos y manifiestan diversos grados de desactualización, abandono o desuso que los pone en peligro de desaparecer, pero a la vez les otorga una oportunidad para su reutilización. En el caso del Aeropuerto, su abandono obedece a la falta de funcionamiento como tal a lo largo de su historia. En el caso de los Silos, por el desmantelamiento del acopio y distribución de trigo en $\mathrm{Co}^{-}$ lombia después de haber funcionado por cincuenta años. Y en el caso de la Normal, el funcionamiento actual como Universidad indica que se ha mantenido su vitalidad como conjunto educativo, pero que podría ser afectado por condiciones técnico estructurales territarias 33 
como la adecuación a normativas de sismo resistencia y accesibilidad reguladas en Colombia mucho después de su original construcción.

- Los tres elementos constituyen huellas con capacidad de contar historias y juegan un papel importante en la configuración morfológica de Tunja.

Por su valor arquitectónico, urbanístico y testimonial, se recomienda reusar los elementos patrimoniales difusos (Calderón \& Ruiz-Valdepeñas, 2007), mediante intervenciones que, de manera análoga a lo que sucede en diversos lugares del planeta, adquieran un nuevo estatus para el conjunto de la sociedad a tono con la premisa medioambiental donde es mejor reusar que botar a la basura, en este caso, demoler las edificaciones. Son múltiples las iniciativas de intervención y las posibilidades que estos brindan para albergar nuevos usos y enseñar, desde su propia arqueología, aspectos que interesan a la memoria colectiva.

\section{Agradecimientos}

A Nancy Camacho Pérez, Ana María Molano Bautista, por su participación en el proceso de selección de los elementos del patrimonio difuso. De igual forma, a Carmenza Montañez Torres, Christian Felipe Vera Gómez, Erika María Sandoval Valero, Fabio Nelson Rodríguez Díaz, Liliana Paola Muñoz Gómez, Luis Oliverio Chaparro Lemus, Mónica Marcela Sánchez Duarte, Clara Patricia Avella Ibáñez, Carlos Andrés Carreño, Julián Llanos, Iván Mauricio
Torres y Santiago Llanos quienes, como integrantes del equipo de trabajo de este proyecto, han brindado sus aportes para la identificación de variables y la realización de los procedimientos conducentes a la incorporación de los objetos del recorrido inicial de Mutua. A Daniela Ruíz por el apoyo con la diagramación de imágenes de apoyo a este texto.

\section{Referencias}

Aguirre, B. (2007). Del concepto de bien histórico-artístico al de Patrimonio Cultural. DU \& P: revista de diseño urbano y paisaje, $4(11), 1-34$.

AUA (1958). Tunja 1958-1985: Plan piloto Ciudad. Bogotá: Arquitectos Urbanistas Asociados (AUA), Editorial Centro Interamericano de Vivienda y Planeamiento e Instituto de Crédito Territorial.

Barreto, M. (1993). Paradigmas Actuales de la Museología. Recuperado de http:// www.naya.org.ar/articulos/museologia01.htm

Benevolo, L. (2008). Historia de la arquitectura moderna (8. ${ }^{a}$ ed.). Barcelona: Gustavo Gili.

Boriani, M. (2014). El paisaje "histórico": algunos aspectos sobre tutela, manutención y uso. Designia, 2(2), 94-113.

Boriani, M., \& Giambruno, M. C. (2008). Teaching of restoration at Scholl of Civil Arquitecture of Politecnico di Milano: doctrine, contents, teaching methods and perspectives. En S. Musso, \& L. de Marco (Eds.), Teaching conservation/ 
restoration of the architectural heritage goals, contents and methods. Vol. Transactiuons on Architectural Education 38, (pp. 303-308). Genoa: University of Genoa.

Calderón, B., \& Ruiz-Valdepeñas, H. P. (2007). El lugar del patrimonio industrial en los procesos de transformación urbana: de la ruina a la explotación de las reliquias fabriles en Valladolid. Ería, 55-73.

Carpio, C. U. del (2014). Espacios públicos, identidad y segregación socio territorial en el sector noroccidental de Tunja. En J. Llanos (Ed.), La montaña sagrada de Tunja (pp. 13-21). Tunja: Ediciones Universidad de Boyacá.

Decarli, G. (2003). Vigencia de la Nueva Museología en América Latina: conceptos y modelos. Abra, 24(33), 1-22. Recuperado de http://www.sernageomin. cl/Museo_Geologico/documentos/ Edit3_Art_VigenciaNM.pdf

Espinal, C. F., Martínez, H., \& Prieto, L. (2006). La cadena del trigo en Colombia. Ministerio de Agricultura y Desarrollo Rural. Bogotá: Observatorio Agrocadenas Colombia.

Fenalce (2007). El buen momento del trigo. El cerealista, 4-8.

Fondo Nacional Cerealista (enero-febrero, 2007). Crisis en la Comercialización del Trigo. Coyuntura cerealista (11), 1-2. Recuperado de http://fenalce.org/ arch_public/Coyunturallb_co.pdf

Fondo Nacional Cerealista (2007). Deflación en el precio de los alimentos. Perspectivas cerealistas $38,1-7$.
García, de M. D. (2007). La arquitectura y el poder en Bogotá durante el gobierno del General Gustavo Rojas Pinilla, 1953-1957. Revista de Arquitectura, $9(1), 18-25$.

Hidalgo, A. (2010). Morfología y actores urbanos en la periferia urbana. Caso Tunja, Boyacá 1908-2005 (Tesis doctoral, Universidad Politécnica de Madrid, Madrid, España). Recuperado de http:// oa.upm.es/5963/

Hidalgo, A. (2012). Tunja: primera modernización, aniversarios y obras públicas (1905-1939). Tunja: Ediciones Universidad de Boyacá.

Hidalgo, A. (2014). Tunja: Transformación urbana a partir de la vivienda obrera (1940-1957). Tunja: Ediciones Universidad de Boyacá.

Llanos, J. (2012). Memoria y sentidos: esculturas públicas y monumentos de Tunja en comunicación con la ciudad. Tunja: Ediciones Universidad de Boyacá.

Llanos, J., Hidalgo-Guerrero, A., \& Torres, I. M. (2014). Identificación e incorporación de elementos del patrimonio urbano difuso tunjano al Ciberecomuseo "Mutua". Designia 3(1), 92-121.

Martínez, A. (1986). Planes de desarrollo y politica agraria en Colombia: 19401978. Bogotá: Universidad Nacional de Colombia.

Medina, E. (2007). Flórez. Costumbres Tunjanas del Siglo XX. Tunja: Alcaldía Mayor de Tunja, Secretaría de Cultura y Turismo.

Miranda, A. (2005). Un canon de arquitectura moderna. Madrid: Cátedra. territarios 33 
Navarro, O. (2006). Museología y capacitación: los retos de la enseñanza museológica vistos desde la museología critica. Ponencia presentada en el XxIX Congreso Anual del ICOFOM / XV CONGRESO Regional del ICOFOMA-LAM- http:// documentos.ilam.org/ILAMDOC/ MuseologiaCapacitacion.pdf. Córdoba y Alta Gracia.

Niño, M. C. (1999). Arquitectura y Estado. Bogotá: Universidad Nacional de Colombia.
Norberg-Schulz, C. (2005). Los principios de la arquitectura moderna: sobre la nueva tradición del siglo XX. Barcelona: Reverté.

Ortega, D., Fariña, D., \& Junior, F. (Dirs.) (2013). Arquitectura en la dictadura de Gustavo Rojas Pinilla, Colombia 1953-1957 [Película]. https://www. youtube.com/watch?v=h3wj5TmXqdo

Pastor, H. M. I. (2004). Pedagogía museistica: nuevas perspectivas y tendencias actuales. Barcelona: Ariel. 